\title{
KUALITAS BAMBU LAMINASI ASAL KABUPATEN TORAJA, SULAWESI SELATAN
}

\section{(Qualities of Laminated Bamboo of Toraja Regency, Soutb Sulawesi)}

\author{
Oleh/By :
}

Misdarti $^{1)}$

\begin{abstract}
The research aimed to find the effect of bamboo species and types of poly vinyl acetate (PVAc) glue on physical and mechanical properties of laminated bamboo assembly. Bamboo species were bitam and parring. Meanwbile, PVAc glue types were fox, tiger, and epoxy. Initially, air dry bamboo specimens each measuring $51 \mathrm{~cm}$ by $2.5 \mathrm{~cm}$ by $0.5 \mathrm{~cm}$ were prepared and then used to construct laminated assembly. Afterwards, each of the bamboo specimens was glue-spread on its bonding area with 200 grams of glue per $\mathrm{cm}^{2}$ (single glueline). A pair of bamboo specimens with the same species was then bonded together into laminated assembly, bydraulically pressed at room temperature for 12 bours, and subsequently conditioned at room temperature as well for one week.

It turned out that different PVAc glue types did not significantly affect the physical and mechanical properties of the laminated assembly made up of bitam and parring bamboo species. On the other hand, laminated bamboo assembly bonded together with PVAc glue of epoxy type tended to have greater MOE and glue shear strength than those using the other two PVAc glue types. The greatest gluing eficiency occurred at laminated assembly of parring bamboo with PVAc's epoxy.
\end{abstract}

Keywords: Laminated bamboo assembly, PVAcglue types, physical and mechanicalproperties

\begin{abstract}
ABSTRAK
Penelitian ini bertujuan untuk mempelajari pengaruh jenis bambu dan macam perekat poly vinyl acetate (PVAc) terhadap sifat fisis dan mekanis bambu laminasi. Jenis bambu yang digunakan adalah hitam dan parring. Sedangkan macam perekat PVAc yang digunakan adalah fox, tiger dan epoxy. Bambu laminasi dibuat dengan menggunakan bambu kering udara dengan ukuran 51 x 2,5 x 0,5 cm. Kemudian sampel bambu dilaburi perekat secara merata pada salah satu sisi dengan berat labur 200 $\mathrm{gr} / \mathrm{m}^{2}$. Selanjutnya sampel bambu dari jenis yang sama direkat satu sama lain kemudian dikempa pada suhu ruangan dengan menggunakan klem selama 12 jam. Bambu lamina kemudian dikondisikan pada suhu ruangan selama 1 minggu.
\end{abstract}

${ }^{1)}$ Peneliti pada Balai Litbang Kehutanan Sulawesi, Makasar 
Hasil penelitian menunjukkan bahwa perbedaan macam perekat berpengaruh tidak nyata terhadap sifat fisis dan mekanis bambu laminasi yang dibuat dari bilah bambu hitam dan bambu parring. Bambu laminasi dengan menggunakan lem epoxy cenderung memiliki nilai MOE dan keteguhan rekat yang lebih baik dibanding lem fox dan lem tiger. Efisiensi perekatan terbesar terjadi pada bambu laminasi parring dengan lem epoxy.

Kata kunci : Bambu laminasi, macam perekat PVAc, sifat fisis dan mekanis

\section{PENDAHULUAN}

Bambu tergolong tumbuhan serbaguna karena dapat dimanfaatkan untuk berbagai kebutuhan hidup, mulai sebagai bahan makanan (rebung), komponen bangunan, hiasan/ dekorasi, peralatan dapur, jembatan ringan, bahan pembuat kertas, dan alat musik. Beberapa alasan bambu tepat dikembangkan karena bisa hidup disemua musim dan tempat, mempunyai umur tebang relatif singkat (4 - 5 tahun), mudah ditanam, mempunyai sifat kekuatan yang relatif tinggi, sehingga memiliki peluang yang besar sebagai pengganti kayu. Selain itu, bambu relatif murah dan membutuhkan lebih sedikit pengerjaan daripada kayu.

Walaupun demikian, bambu memiliki beberapa kelemahan antara lain bambu mudah terserang kumbang bubuk, sehingga barang atau perabot yang terbuat dari bambu tidak awet. Adanya opini masyarakat yang sering menghubungkan bambu dengan kemiskinan, sehingga masyarakat enggan menggunakan bambu juga merupakan kendala dalam pemanfaatan bambu. Untuk itu perlu dilakukan peningkatan kualitas bambu dengan berbagai teknik.

Diperkirakan terdapat 1.000 jenis bambu dari 80 genera di dunia dan dari jumlah tersebut 200 jenis dari 20 genera dijumpai di Asia Tenggara (Dransfield dan Widjaja, 1995). Menurut hasil identifikasi Balai Rehabilitasi Lahan dan Konservasi Tanah (BRLKT) Wilayah IX (1997), di Sulawesi Selatan terdapat sekitar 11.881 ha lahan bambu yang tersebar di 14 kabupaten dengan produksi total setiap tahunnya mencapai 28.960 batang/ha. Kabupaten Tana Toraja memiliki luas areal bambu terbesar yaitu 6.071 ha, dikuti oleh Kabupaten Gowa dan Maros dengan luas areal masing-masing 1.600 ha dan 1.125 ha.

Umumnya masyarakat Toraja mengenal 6 jenis bambu yang banyak digunakan dalam kehidupan sehari-hari yaitu pattung (Dendrocalamus asper), parring (Schizotachyum zollingeri Stend.), talang (Schizotachyum brachycladum Kurz.), ao'maido (Gigantochloa utter Hassk.), ao'mariri (Bambusa vulgaris Schrad.) dan bulo (jenis bambu kecil). Bambu umumnya digunakan sebagai bahan bangunan sederhana, bahan bakar, tempat masak, pemanpung air, alat musik dan hiasan (Sallata, 1998). Sedangkan di kabupaten Gowa terdapat beberapa jenis bambu yang potensial yaitu bambu berduri, bambu parring dan bambu pettung.

Salah satu teknik peningkatan kualitas bambu adalah melalui teknik laminasi. Menurut Tsoumis (1991), beberapa kelebihan balok atau bambu laminasi antara lain dapat dihasilkan balok dengan berbagai bentuk dan ukuran yang sesuai dengan tujuan pemakaian, dapat memanfaatkan bambu yang berdimensi kecil, serta kekuatan dan keawetannya dapat ditingkatkan dengan perlakuan-perlakuan tertentu.

Dalam pembuatan bambu laminasi diperlukan jenis perekat yang tepat agar bilah bambu yang direkatkan dapat menyatu secara optimal. Selain itu setiap jenis bambu memiliki sifat 
yang berbeda sehingga diperlukan pemilihan jenis yang paling baik untuk digunakan dalam pembuatan bambu laminasi. Oleh karena itu dalam penelitian ini dilakukan pembuatan bambu laminasi dari 2 jenis bambu dengan menggunakan 3 jenis perekat PVAc. Dengan demikian dapat diketahui pengaruh jenis bambu dan macam perekat terhadap sifat fisis dan mekanis bambu hasil laminasi.

Tujuan penelitian untuk mengetahui pengaruh jenis bambu dan jenis perekat terhadap sifat fisis dan mekanis bambu laminasi. Sasaran penelitian adalah tersedianya jenis bambu dan jenis perekat yang sesuai untuk bambu laminasi.

\section{METODE PENELITIAN}

\section{A. Bahan dan Alat}

Bahan yang digunakan adalah 2 jenis bambu yang berumur 6 tahun (bambu hitam dan bambu parring) dan 3 jenis perekat PVAc (Fox, Tiger dan Epoxy). Alat yang digunakan antara lain gergaji, parang, mesin serut, alat pres, mistar, kaliper, timbangan, kuas dan lain-lain.

\section{B. Pembuatan Contoh Uji}

Batang bambu dipotong sepanjang $200 \mathrm{~cm}$. Selanjutnya masing-masing bambu diambil ruasnya dengan panjang $51 \mathrm{~cm}$ dan dibelah menjadi 4-6 belahan (tergantung besarnya diameter bambu), belahan bambu dibuang kulit bagian luar dan dalamnya, kemudian dikeringudarakan sampai mencapai kadar air 12 - 15\%. Selanjutnya diketam sehingga diperoleh bilah bambu dengan panjang $51 \mathrm{~cm}$, lebar $2.5 \mathrm{~cm}$ dan tebal $0.5 \mathrm{~cm}$. Kemudian dibuat bambu laminasi dengan jumlah lapisan 5 buah, dengan menggunakan 3 jenis perekat PVAc.

\section{Pembuatan Bambu Laminasi}

Bilah bambu yang telah kering dihaluskan dan dibersihkan untuk mempermudah proses perekatan. Kemudian bilah bambu disusun satu sama lain dan direkat dengan berat labur 200 gr/m2 dan dikempa dengan menggunakan klem dengan waktu kempa 12 jam. Bambu laminasi selanjutnya dikondisikan selama 1 minggu agar daya rekat kayu benar-benar konstan.

\section{Pengujian Sifat Fisis dan Mekanis Bambu Laminasi}

Sifat fisis dan mekanis yang diuji meliputi kadar air, berat jenis, keteguhan lengkung (MOE dan MOR) dan keteguhan rekat, berdasarkan standar JAS (Anonim, 2003) serta efisiensi perekatan.

\section{E. Analisa Data}

Dalam penelitian ini digunakan Rancangan Acak Kelompok (RAK) dengan faktor perlakuan (Gaspersz, 1994): macam perekat yang terdiri dari Fox, Tiger dan Epoxy dan kelompok : jenis bambu yang terdiri dari bambu hitam dan bambu parring. Tiap taraf dari kombinasi macam perekat dan jenis bambu dilakukan ulangan sebanyak 3 kali. Apabila hasil 
analisis ragam menunjukkan ada pengaruh nyata secara statistik (pada $\alpha=1$ atau $5 \%$ ), selanjutnya dilakukan uji Tukey (Beda Nyata Jujur) dan BNT (Beda Nyata Terkecil).

\section{HASIL DAN PEMBAHASAN}

Nilai rata-rata hasil pengujian sifat fisis dan mekanis bambu laminasi disajikan pada Tabel 1. Untuk mengetahui pengaruh jenis perekat terhadap sifat fisis dan mekanis bambu laminasi, dilakukan analisis sidik ragam dan hasilnya tersaji pada Tabel 2.

Kadar air bambu laminasi berkisar antara 9,26 - 11,39\%. Sedangkan kerapatan bambu laminasi berkisar antara 0,55-0,69. Hasil sidik ragam menunjukkan bahwa jenis perekat berpengaruh tidak nyata terhadap kadar air dan kerapatan bambu laminasi. Kadar air kering udara bambu hitam sebelum laminasi 9,95\% dengan kerapatannya 0,66. Sedangkan kadar air kering udara bambu parring sebelum laminasi 10,00\% dengan kerapatan 0,66. Pada umumnya kerapatan produk komposit dipengaruhi oleh kerapatan bahan penyusunnya, perekat dan proses pengempaan (Sulastiningsih, dkk., 2004).

Tabel 1. Nilai rata-rata sifat fisis dan mekanis bambu laminasi 1) Table 1. Average of physical and mechanical properties of laminated bamboo1)

\begin{tabular}{|c|c|c|c|c|}
\hline \multirow{2}{*}{$\begin{array}{c}\text { Sifat/jenis bambu } \\
\text { (Properties/bamboo species) }\end{array}$} & \multirow{2}{*}{$\begin{array}{l}\text { Kontrol sebelum } \\
\text { dilaminasi } \\
\text { (Control before being } \\
\text { laminated) }\end{array}$} & \multicolumn{3}{|c|}{$\begin{array}{c}\text { Macam perekat } \\
\text { (Kind of glue/adhesive) }\end{array}$} \\
\hline & & Fox & Tiger & Epoxy \\
\hline $\begin{array}{l}\text { Kadar air (Moisture content), \%: } \\
\text { Bambu hitam } \\
\text { Bambu parring }\end{array}$ & $\begin{array}{c}9,95 \\
10,00\end{array}$ & $\begin{array}{l}9,38 \\
9,26\end{array}$ & $\begin{array}{c}11,39 \\
9,78\end{array}$ & $\begin{array}{l}9,28 \\
9,53\end{array}$ \\
\hline $\begin{array}{l}\text { Kerapatan (Density), } \mathrm{g} / \mathrm{cm}^{2}: \\
\text { Bambu hitam } \\
\text { Bambu parring }\end{array}$ & $\begin{array}{l}0,66 \\
0,66\end{array}$ & $\begin{array}{l}0,60 \\
0,69\end{array}$ & $\begin{array}{l}0,56 \\
0,66\end{array}$ & $\begin{array}{l}0,55 \\
0,68\end{array}$ \\
\hline $\begin{array}{l}\text { Modulus elastisitas }(\mathrm{MOE}) \text {, } \\
\mathrm{kg} / \mathrm{cm}^{2} \text { : } \\
\text { Bambu hitam } \\
\text { Bambu parring }\end{array}$ & $\begin{array}{l}4.287,71 \\
4.366,63\end{array}$ & $\begin{array}{l}1.394,12 \\
1.747,31\end{array}$ & $\begin{array}{l}1.324,89 \\
1.512,50\end{array}$ & $\begin{array}{l}1.606,86 \\
1.815,93\end{array}$ \\
\hline $\begin{array}{l}\text { Modulus patah }(M O E), \mathrm{kg} / \mathrm{cm}^{2} \text { : } \\
\text { Bambu hitam } \\
\text { Bambu parring }\end{array}$ & $\begin{array}{l}1.253,92 \\
1.359,41\end{array}$ & $\begin{array}{l}820,48 \\
828,46\end{array}$ & $\begin{array}{l}731,50 \\
859,38\end{array}$ & $\begin{array}{l}808,86 \\
843,60\end{array}$ \\
\hline $\begin{array}{l}\text { Keteguhan rekat (Glue shear strength), } \\
\mathrm{kg} / \mathrm{cm}^{2} \text { : } \\
\mathrm{Bambu} \text { hitam } \\
\text { Bambu parring }\end{array}$ & $\begin{array}{l}- \\
-\end{array}$ & $\begin{array}{c}81,80 \\
117,85 \\
\end{array}$ & $\begin{array}{c}69,78 \\
112,89 \\
\end{array}$ & $\begin{array}{c}70,42 \\
121,25 \\
\end{array}$ \\
\hline $\begin{array}{l}\text { Efisiensi perekatan (Gluing efficiency), } \\
\% \text { : } \\
\text { Bambu hitam } \\
\text { Bambu parring }\end{array}$ & $\begin{array}{l}- \\
-\end{array}$ & $\begin{array}{l}32,51 \\
40,02\end{array}$ & $\begin{array}{l}30,90 \\
34,64\end{array}$ & $\begin{array}{l}37,48 \\
41,59\end{array}$ \\
\hline
\end{tabular}

${ }^{1)}$ Rata-rata 3 ulangan (Average of 3 replications) 
Tabe1 2. Analisa keragaman sifat fisis dan mekanis bambu laminasi

Table 2. Analysis of variances on physical and mechanical properties of laminated bamboo

\begin{tabular}{|c|c|c|c|c|c|c|}
\hline \multirow[b]{2}{*}{$\begin{array}{l}\text { Sumber keragaman } \\
\text { (Source of variation) }\end{array}$} & \multirow[b]{2}{*}{$\begin{array}{l}\mathrm{Db} \\
(d f)\end{array}$} & \multicolumn{5}{|c|}{ F-hitung (F-calculated) } \\
\hline & & $\begin{array}{l}\text { Kadar air } \\
\text { (Moisture } \\
\text { content) }\end{array}$ & $\begin{array}{c}\text { Kerapatan } \\
\text { (Density) }\end{array}$ & $\begin{array}{c}\text { Modulus } \\
\text { elastisitas } \\
\text { (MOE) }\end{array}$ & $\begin{array}{l}\text { Modulus } \\
\text { patah } \\
(M O R)\end{array}$ & $\begin{array}{l}\text { Keteguhan } \\
\text { rekat (Glue } \\
\text { shear strength) }\end{array}$ \\
\hline $\begin{array}{l}\text { Total } \\
\text { Jenis bambu } \\
\text { (Bambu species), A }\end{array}$ & $\begin{array}{l}5 \\
1\end{array}$ & & & & & \\
\hline $\begin{array}{l}\text { Macam perakat } \\
\text { PVAc (PVAc glue } \\
\text { types), B } \\
\text { Sisa (Residuals) }\end{array}$ & 2 & 2.063 tn & 3.308 th & 10.572 tn & 0.302 tn & 1.321 tn \\
\hline Rata-rata (Means) & - & $\begin{array}{c}9.77 \\
0 \%\end{array}$ & $\begin{array}{c}0.62 \\
\sigma / \mathrm{cm}^{2}\end{array}$ & $\begin{array}{l}1.566 .94 \\
\mathrm{~kg} / \mathrm{cm}^{2}\end{array}$ & $\begin{array}{c}815.38 \\
\mathrm{ko} / \mathrm{cm}^{2}\end{array}$ & $\begin{array}{c}95.67 \\
\mathrm{ko} / \mathrm{cm}^{2}\end{array}$ \\
\hline $\begin{array}{l}\text { Koefisien } \\
\text { keragaman (Coeff. } \\
\text { of variation), } \%\end{array}$ & - & 0.709 & 0.977 & 0.957 & 0.604 & 0.981 \\
\hline
\end{tabular}

Keterangan (Remarks) $:$ tn = tidak nyata (not significantly different)

Modulus elastisitas (MOE) bambu laminasi berkisar antara 1.324,89-1.815,93 kg/ cm². Bambu laminasi dengan menggunakan lem epoxy cenderung mempunyai modulus elastisitas yang lebih tinggi. Hal ini kemungkinan disebabkan daya rekat epoxy lebih kuat dibandingkan dengan jenis perekat lain. MOE bilah bambu hitam sebelum dilaminasi sebesar 4.287,71 $\mathrm{kg} / \mathrm{cm}^{2}$, sedangkan bambu parring sebesar 4.366,63 kg/ $\mathrm{cm}^{2}$. MOE bambu laminasi lebih rendah dibandingkan bilah bambu sebelum dilaminasi. Hasil sidik ragam menunjukkan bahwa jenis perekat berpengaruh tidak nyata terhadap MOE bambu laminasi. Hal ini diduga dipengaruhi oleh kualitas perekat yang digunakan. Pada saat pengujian terlihat bahwa garis rekat dari balok laminasi banyak yang bergeser sehingga kemampuan untuk menahan beban hanya bisa ditahan oleh lapisan atas. Dengan kata lain perekat tidak mampu menyatukan bambu secara maksimal sehingga mempengaruhi struktur bambu pada saat pembebanan. Menurut Dransfield dan Widjaja (1995), semakin besar nilai MOE maka bahan tersebut semakin kaku. MOE berhubungan langsung dengan jumlah serat pada kayu.

Modulus patah (MOR) bambu laminasi berkisar antara 731,50 - 859,38 kg/ $\mathrm{cm}^{2}$. MOR bilah bambu hitam sebelum dilaminasi sebesar 1.253,92 kg/ $\mathrm{cm}^{2}$, sedangkan bambu parring sebesar 1.359,41 kg/ $\mathrm{cm}^{2}$. MOR bambu laminasi lebih rendah dibandingkan bilah bambu sebelum dilaminasi. Hasil sidik ragam menunjukkan bahwa jenis perekat berpengaruh tidak nyata terhadap MOR bambu laminasi. Sama halnya dengan MOE, hal ini diduga dipengaruhi oleh kualitas perekat. Keteguhan rekat yang dihasilkan cukup rendah sehingga kemampuan balok untuk menahan beban sampai batas patah kecil. Dari hasil pengujian, garis rekat bambu laminasi mengalami pergeseran sebelum balok patah, sehingga nilai MOR yang dihasilkan rendah. Menurut Janssen (1981), kekuatan lentur bambu dipengaruhi oleh posisi dalam batang dan ada tidaknya buku. 
Keteguhan rekat bambu laminasi berkisar antara 69,78-121,25 kg/ $\mathrm{cm}^{2}$. Hasil sidik ragam menunjukkan bahwa jenis perekat berpengaruh tidak nyata terhadap keteguhan rekat bambu laminasi. Menurut Samiun (1995), nilai keteguhan rekat dipengaruhi oleh kandungan padat dari perekat. Semakin tinggi kandungan padat maka kadar resin akan semakin tinggi, hal ini menunjukkan bahwa perekat tersebut berkualitas baik. Selain itu, keteguhan rekat juga dipengaruhi oleh kadar abu perekat. Semakin tinggi kadar abu maka semakin rendah proses pelunakan dari perekat, dengan kata lain nilai keteguhan rekatnya akan semakin rendah.

Efisiensi perekatan berkisar antara 30,90 - 41,59\%. Efisiensi perekatan terbesar terjadi pada bambu laminasi yang menggunakan bambu parring dengan lem epoxy. Sedangkan efisiensi perekatan terendah terjadi pada bambu laminasi yang menggunakan bambu hitam dengan lem tiger. Hal ini diduga dipengaruhi oleh kondisi permukaan bambu dan daya rekat dari perekat. Bambu parring memiliki serat yang lebih halus dibanding bambu hitam sehingga perekat lebih mudah untuk menyatukan bilah bambu. Selain itu, perekat epoxy diduga memiliki daya rekat yang lebih baik dibanding lem fox dan lem tiger, sehingga efisiensi perekatan dengan menggunakan lem epoxy lebih baik.

Menurut Janssen (1981), sifat fisis dan mekanis bambu dipengaruhi oleh jenis dan umur bambu, kondisi bambu, kadar air, bentuk dan ukuran contoh, buku atau tidak berbuku, posisi dalam batang dan lamanya pembebanan.

\section{KESIMPULAN}

Jenis perekat tidak berpengaruh terhadap sifat fisis dan mekanis bambu laminasi yang dibuat dari bilah bambu hitam maupun bambu parring.

Bambu laminasi parring dengan menggunakan lem epoxy memiliki nilai MOE dan keteguhan rekat yang lebih baik dibandingkan bambu laminasi parring dengan dengan menggunakan lem fox maupun lem tiger.

Efisiensi perekatan bambu laminasi dengan menggunakan lem epoxy lebih baik dibanding lem fox dan lem tiger.

Efisiensi perekatan bambu laminasi dengan menggunakan bambu parring lebih baik dibanding bambu hitam.

\section{DAFTAR PUSTAKA}

Anonim. 2003. Japanese agricultural standard for glued laminated timber. MAFF, Notification No. 234. Japan Plywood Inspection Corporation. Tokyo.

2000. Himpunan sari hasil penelitian rotan dan bambu. Pusat Penelitian Hasil Hutan. Bogor.

Dransfield, S dan E.A. Widjaja (Editors). 1995. Plant resources of south east asia (PROSEA)

No. 7 : Bamboos. Backhuys Publishers, Leiden.

Gaspersz, V. 1994. Metode Perancangan Percobaan. Penerbit Armico. Bandung. 
Janssen, J.J.A. 1981. Bamboo in building structures. Doctor's Thesis TH Eindhoven. Netherland (Unpublished).

Sallata, M.K. 1998. Hutan bambu dan keberadaannya di kabupaten Tana Toraja, Sulawesi Selatan. Eboni (semi popular), 3 (2). Balai Penelitian Kehutanan Ujung Pandang.

Samiun, S. 1995. Pengaruh waktu kempa dan jenis perekat terhadap sifat keteguhan rekat balok laminasi produksi PT. Mutiara Sotia Hijau Jakarta. Skripsi Jurusan Teknologi Hasil Hutan, Fakultas Kehutanan IPB. Bogor. Tidak diterbitkan.

Sulastiningsih, I.M., Nurwati dan Adi Santoso. 2004. Pengaruh lapisan kayu terhadap sifat bambu lamina. Prosiding Seminar Nasional Masyarakat Peneliti Kayu Indonesia (MAPEKI) VII, tanggal 5-6 Agustus 2004 di Makassar. Hlm. B148-153. Masyarakat Peneliti Kayu Indonesia, Balai Penelitian dan Pengembangan Kehutanan Sulawesi dan Jurusan Kehutanan Universitas Hasanuddin. Makassar.

Tsoumis, G. 1991. Science and Technology of Wood Structure, Properties, Utilization. Van Nostrand Reinhold. New York.

\section{Ucapan Terima Kasih}

Penulis mengucapkan terima kasih yang sebesar-besarnya kepada Ibu Ir. Nurwati Hadjib, MS dan Bapak Profesor Riset Dr. Ir. Osly Rahman, MS atas bantuan dan bimbingannya dalam pelaksanaan penelitian. 